\title{
A Hybrid PSO-ANFIS Approach for Horizontal Solar Radiation Prediction in Nigeria
}

\author{
Sani Salisu ${ }^{1,2 *}$, Mohd Wazir Mustafa ${ }^{1}$, Mamunu Mustapha ${ }^{1}$, Abdulrahman Okino Otuoze ${ }^{3}$ and Olatunji \\ Obalowu Mohammed ${ }^{3}$
}

\author{
${ }^{1}$ School of Electrical Engineering, Faculty of Engineering, university Teknologi Malaysia, \\ 81310 UTM Skudai, Johor, Malaysia \\ ${ }^{2}$ Department of Electrical Engineering, Ahmadu Bello University, Zaria, Kaduna State, Nigeria. \\ ${ }^{3}$ Department of Electrical and Electronics Engineering, University of Illorin, Kwara State, Nigeria
}

"Corresponding author: s.salisu@live.com

\begin{abstract}
For efficient and reliable hydrogen production via solar photovoltaic system, it is important to obtain accurate solar radiation data. Though there are equipment specifically designed for solar radiation prediction but are very expensive and have high maintenance cost that most countries like Nigeria are unable to purchase. In this study, the accuracy of a hybrid PSOANFIS method is examined to predict horizontal solar radiation in Nigeria. The prediction is done based on the available meteorological data obtained from NIMET Nigeria. The meteorological data used for this study are monthly mean minimum temperature, maximum temperature, relative humidity and sunshine hours, which serves as inputs to the developed model. The model accuracy is evaluated using two statistical indicators Root Mean Square Error (RMSE) and Coefficient of determination $\left(\mathrm{R}^{2}\right)$. The accuracy of the proposed model is validated using ANFIS, GA-ANFIS models and other literatures. Based on the statistical parameters used for the model evaluation, the results obtained proves PSO-ANFIS as a good model for predicting solar radiation with the values of $\mathrm{RMSE}=0.68318, \mathrm{R}^{2}=0.9065$ at the training stage and $\mathrm{RMSE}=1.3838, \mathrm{R}^{2}=0.8058$ at the testing stage. This proves the potentiality of PSO-ANFIS technique for accurate solar radiation prediction.
\end{abstract}

Keywords: Solar radiation, PSO-ANFIS, GA-ANFIS, Prediction, Nigeria.

(C) 2019 Penerbit UTM Press. All rights reserved

\section{INTRODUCTION}

Solar energy in Nigeria has been recognized as one of the most available, clean and reliable renewable energy source. It is free, environmentally friendly and available in rich quantity [1]. Precise knowledge of horizontal solar radiation is crucial for every successful solar power design [2]. Due to the current transition towards clean energy production and hydrogen economy as a result of fossil fuels depletion and environmental pollution, hydrogen production via renewable sources has gained a lot of attention especially using photovoltaic systems in places where there is no electricity access [3]. Hydrogen being highly efficient and has very low pollution can be utilized for various applications like energy generation, especially in areas with no electricity access [3]. Hydrogen element is highly available in abundant quantity, it can therefore continuously be sustained for energy generation. One of the many ways of producing hydrogen energy is through the use photovoltaic system, this is done by electrolyzing the water without carbon dioxide emission [4, 5]. To produce this hydrogen energy via photovoltaic system, precise knowledge of horizontal solar radiation data is required.

However solar radiation data are not available in some areas. Though there are equipment specifically designed for solar radiation prediction but are very expensive and cannot be acquired by most of the developing countries, these equipment also have a very high maintenance cost and are prone to environmental hazard, these among other factors contribute to non-patronage of the equipment [6]. This results to the development of various algorithms for predicting horizontal solar radiation using the meteorological data available in the study areas [7]. Nigeria as a case study, has a few meteorological stations that are owned by the government, due to the unavailability of the solar radiation measuring equipment in these stations, Nigeria does not have record of solar radiation data. In some of these stations you hardly get a complete record of meteorological data including the temperature, sunshine hour etc. This necessitates the development of various algorithms for horizontal solar radiation prediction.

Angstrom [8] was the first to estimate solar radiation by developing empirical models, his model was first developed by relating sunshine hours clear sky index. Since then, several researchers $[9,10]$ have utilized empirical models for solar radiation estimation. Based on the researches carried out, the empirical models developed illustrate a good correlation between the measured and estimated horizontal solar radiation. Although the models 
are categorized into groups, sunshine duration fraction (SDF), modified sunshine duration fraction (MSDF) and non-sunshine duration fraction (NSD) [11]. The SDF only uses sunshine duration for the estimation, MSDF uses sunshine duration and other meteorological parameters like humidity, temperature, altitude, wind speed, etc. and NSD models do not use sunshine duration for estimation but instead used other meteorological parameters. Based on the models developed by various scholars across the globe, it was concluded that temperature and sunshine duration are the most important parameters for solar radiation estimation.

Over the years, several soft computing techniques have been utilized for solar radiation estimation. These techniques have shown accurate results for the solar radiation estimation. Senkal [12] developed an ANN model estimates solar radiation for twelve cities in Turkey. The result was compared with empirical models, which proves better performance than the empirical models. Qin [13] developed an ANN model and trained it using Larenberg-Marquardt algorithm coupled with Bayesian regulation to train the ANN model and the result obtained proves the model to be a model to predict solar radiation in Saudi Arabia, the model was compared with back propagation neural network (BP-NN) and was proved to perform better than the (BP-NN) model. Benghanem [14] developed six ANN models to predict solar radiation in Saudi Arabia by utilizing different combination of parameters, the obtained result with higher accuracy was temperature and sunshine dependent. Olatomiwa et al and Sani et al [7, 15] developed an ANFIS model to predict solar radiation in Nigeria. The developed models were compared with other literature and found out to outperform the compared models.

Gorka [16] compared several models ANN, GEP, ANFIS and other temperature-based models by using five combination of parameters to find the best model for solar radiation estimation. The optimized ANN gives a more promising result compare to other models. Piri [17] applied support vector machine polynomial (SVMpoly and support vector machine regression (SVMrbf) for solar radiation estimation in two Iranian cities. Their research found SVMrbf to give more accurate results. Bhardwaj [18] evaluated the effect of different meteorological parameters used for solar radiation prediction and proposed a hybrid Markov model and fuzzy models in India. Wu [19] also developed a combined time delay neural network (TDNN) and autoregressive and moving average (ARMA) model to predict hourly solar radiation. Shahaboddin [20] developed a model by training ANN with extreme learning machine (ELM). The result obtained was compared with SVM, ANN and GP models. The developed ELM model produced the best result when compared. Muhammadi [21] proposed a hybrid SVMwavelet model for solar radiation prediction in Iran. The model was compared with ANN, GP and ARMA, the developed model outperforms the ANN, GP and ARMA models. Feng [22] developed four Artificial Intelligence (AI) models, extreme learning machine (ELM), back propagation neural network optimized by genetic algorithm (GANN), random forest (RF) and generalized regression neural network (GRNN) for predicting solar radiation in China. The developed models were compared with empirical Iqbal model where the developed AI models outperform the Empirical Iqbal model with GANN having the best accuracy.

Additionally, Olatomiwa [23] proposed a hybrid SVMFFA model to predict solar radiation in Nigeria and the developed model outperforms the compared GP and ANN models. Huang [24, 25] developed a hybrid model called Coupled AutoRegressive and Dynamic System (CARDS) model for hourly solar radiation prediction in Australia. Xinhua [26] estimated horizontal solar radiation using optimized back propagation neural network (BPNN), the model was optimized by PSO and the obtained result was compared to BPNN and BPNN optimized by GA. The BPNN optimized by PSO provides more accuracy than the compared models.

Generally, PSO-ANFIS is a hybrid approach that combines ANFIS and PSO techniques, the ANFIS is used to train and predict while the PSO optimize or improves the performance of the ANFIS by making sure the error obtained is at its minimal. PSO-ANFIS has been utilized by several scholars for various scientific and engineering applications. Pousinho [27] developed a new PSO-ANFIS model for short-term wind power estimation in Portugal and the result obtained was compared with five other models which the developed hybrid model outperforms the compared models. Also, Pousinho [28] developed a hybrid PSO-ANFIS model for short-term electricity price forecasting in Portugal, results obtained were compared with results from previous researchers to demonstrate the effectiveness of the developed model. Several other scholars [29-36] utilized PSO-ANFIS to solve various scientific and engineering problems. Their results demonstrate the effectiveness and accuracy of this approach. Even though this hybrid approach has been utilized to solve various problems, it is still not utilized in the area of solar radiation estimation, thus making it a novel approach for solar radiation estimation.

In this study, a hybrid PSO-ANFIS method is examined to predict the horizontal solar radiation in Nigeria. The PSO was applied to optimize the ANFIS parameters for better accuracy. The main aim of this study is to examine the aptness of the developed hybrid PSO-ANFIS for horizontal solar radiation estimation. Meteorological data comprising of monthly mean sunshine duration, monthly mean minimum temperature, monthly mean relative humidity and monthly mean maximum temperature were used as the model inputs and monthly mean solar radiation is used as the model output. For this experiment, 10 years data (2002-2012) is used to train and test the model. $70 \%$ of the data set (2002-2009) is used for training while $30 \%$ (2010-2012) is used for testing the model. The effectiveness of the developed PSO-ANFIS is validated by comparing with GA-ANFIS model, ANFIS model and other existing models. 


\section{MATERILAS AND METHODS}

\subsection{Data Collection}

The meteorological data used for this study were collected from Nigerian Meteorological Agency (NIMET) for the period of 10 years, ranging from 1995-2004. Monthly average solar radiation was used as the output. Other meteorological data used as the input are monthly average sunshine hours $(\mathrm{SH})$, relative humidity $(\mathrm{RH})$, minimum temperature (Tmin) and maximum temperature (Tmax). The meteorological data collected were for Kano state Nigeria with a longitude $12.0022^{\circ} \mathrm{N}$ and latitude $8.952^{\circ} \mathrm{E}$, Figure 1 presents the monthly average meteorological data used for the study. The data obtained were divided into two (training data and testing data), the training data sets range from 2002-2009 (70\%) and the testing data set ranges from 2010-2012 (30\%).

\subsection{Particle Swarm Optimization}

PSO is a swarm intelligence optimization algorithm developed by Kennedy and Eberhart in the year 1995 [37]. The algorithm is inspired as a result of the behavior of birds and fishes which is based on their social interactions [38]. As these birds and fishes go randomly in search for food. Each of these birds or fish serve as a single solution, these solutions can be explained as particles in a swarm. In PSO, each of these particles goes in search of a possible solution to a given problem. The movement of these particles is characterized by where they fit best and their current locations with the numbers of the swarm [39].

PSO is considered a population-based search method with each potential solution (a swarm) represents a particle of a population. The particles continue to change their positions during their random search until they attain an optimal state. PSO as an optimization algorithm has been applied to solve several optimization problems and has proved to be a useful tool for solving optimization problems [28], to prove its effectiveness and efficiency. The effectiveness of PSO was shown in previous empirical studies [40].

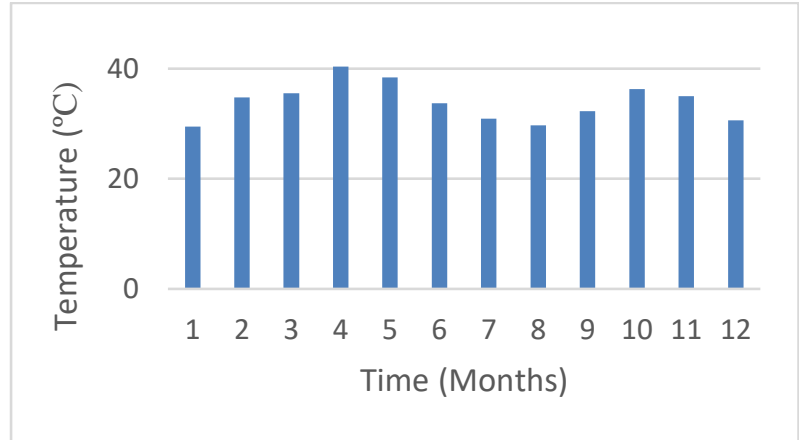

a. Monthly mean maximum temperature

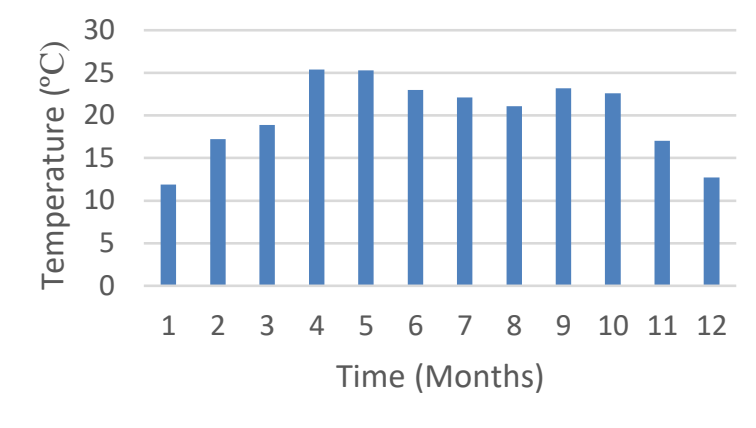

b. Monthly mean minimum temperature

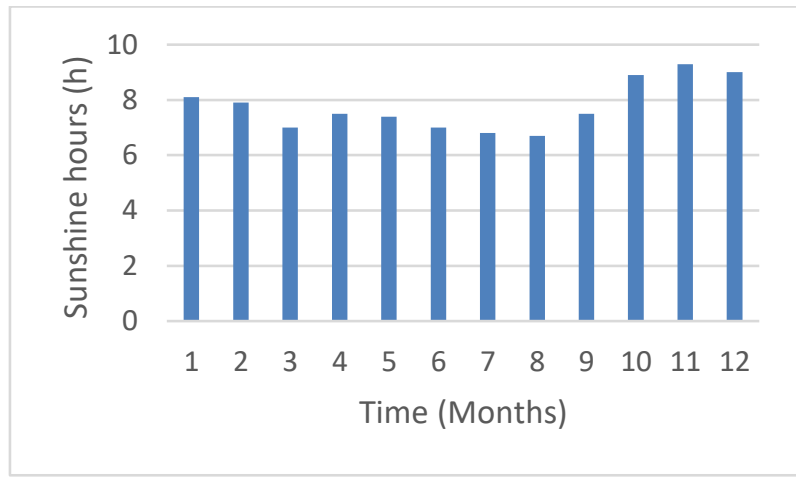

c. Monthly mean sunshine hours

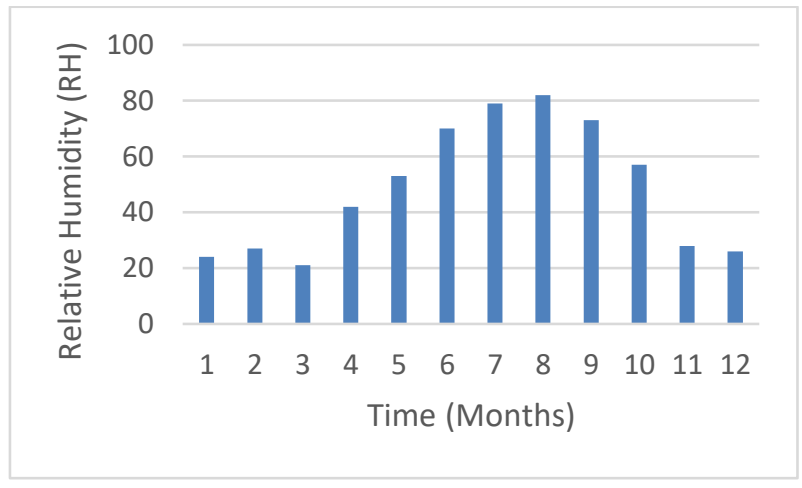

d. Monthly mean relative humidity

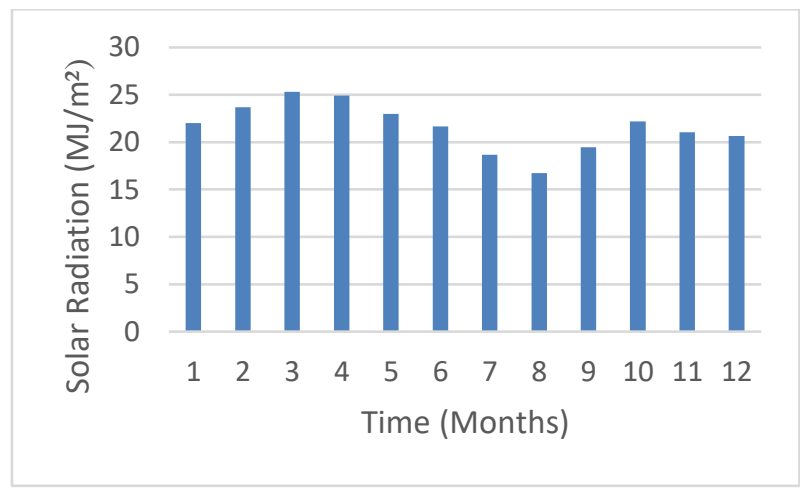

e. Monthly mean solar radiation

Figure 1 (a-e). Monthly mean average data used for the selected area 


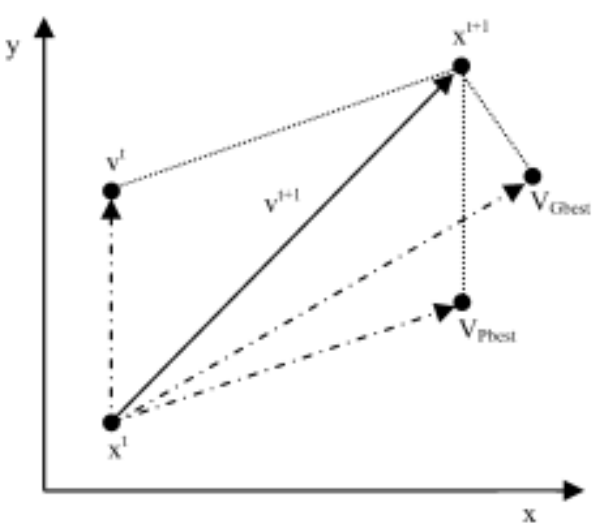

Figure 2. Updating the position mechanism of PSO

In PSO, each particle is associated with its best solution (Pbest) of its coordinate in the problem space. Then followed by another best value (ibest) which is obtained by any particle next to the particle. When a particle takes all the population as the topological neighbors, the best value is called (Gbest) which is the global best value. The velocity vector is updating according to the position of Gbest and Pbest. The equation below illustrates how the velocity and position of a particle are updated. The velocity vector is updating according to the position of Gbest and Pbest.

$$
\begin{aligned}
V_{i}(t)= & w v_{i}(t-1)+\rho_{1}\left(x_{\text {Pbest }_{i}}-x_{i}(t)\right)+ \\
& \rho_{2}\left(x_{\text {Gbest }}-x_{i}(t)\right) \\
x_{i}(t)= & x_{i}(t-1)+v_{i}(t)
\end{aligned}
$$

where $v_{i}(t)$ is the agent velocity at iteration, $x$ is the inertia weight, $w$ is the weighing factor of inertia, $\rho_{1}$ and $\rho_{2}$ are random variables and $\rho_{1}=r_{1} C_{1}$ and $\rho_{2}=$ $r_{2} C_{2}$ with $r_{1}, r_{2} \sim u(0,1)$ and $C_{1}$ and $C_{2}$ are positive acceleration constants. Figure 2 above demonstrate the PSO search mechanism using velocity update rule (1) and position update (2).

\subsection{Adaptive Neuro Fuzzy Approach}

\subsubsection{Neuro Fuzzy Computing}

Recent technologies such as Fuzzy logic, Neural Network, Genetic Algorithm and Adaptive Neuro-Fuzzy Inference System (ANFIS) which are widely used in various scientific and engineering applications for solving various problems are referred to as soft computing techniques. They have various complementary reasoning and searching methods in solving real-world complex problems [41]. In real-life computing problems, combining two or more soft computing methods in a more symbiotic way is better than relying on a single technique. Combining these two techniques like neural network and fuzzy logic, which gives Adaptive Neuro-fuzzy computing is referred to as hybrid intelligent system [42]. Fuzzy logic implements decision-making and differentiation by the use of human knowledge while Neural network recognizes patterns and adapt to cope with the evolving environment [43].

\subsubsection{Adaptive Neuro Fuzzy Inference System}

Adaptive Neuro-Fuzzy Inference System (ANFIS) was first developed by J.S Roger in the year 1993 by combining fuzzy logic system and neural network [44]. The ANFIS is a form of neural network that functions like the Sugenotype "ÍF....THEN" fuzzy inference system rule being a network structure and is considered more efficient than the individual neural network or fuzzy logic system, it provides a more optimal solution than any of the two systems [45]. A typical ANFIS structure is presented in Figure 3 with two inputs $x$ and $y$ and one output $f$, it also consists of five layers with each layer having different function. The ANFIS used for this study comprises of four inputs and a single output. Each of the five layers consists of nodes, the nodes on each layer perform the same functions.

If $\mathrm{x}$ is $\mathrm{A}_{1}$ and $\mathrm{y}$ is $\mathrm{B}_{1}$, then $f_{1}=p_{1} x+q_{1} y+r_{1}$

If $\mathrm{x}$ is $\mathrm{A}_{2}$ and $\mathrm{y}$ is $\mathrm{B}_{2}$, then $f_{2}=p_{2} x+q_{2} y+r_{2}$

Where $p_{i}, q_{i}$, and $r_{i}$ are subsequent parameters.

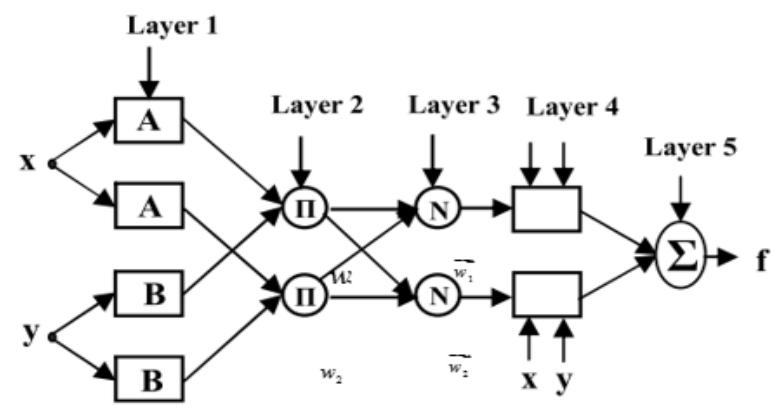

Figure 3. A typical ANFIS structure

Layer 1: The first layer consist of the input membership functions then supplies them to layer two. Each node in layer one has a node function and is also an adaptive node. The nodes output are presented in equations 5 and 6

Or

$$
O_{j, i}=\mu_{A i}\left(x_{i}\right) \quad \text { for } i=1,2
$$

$$
O_{j, i}=\mu_{B i-1}\left(y_{i}\right) \quad \text { for } i=3,4
$$

$\mu_{A i}\left(x_{i}\right)$ and $\mu_{B i-1}\left(y_{i}\right)$, denotes the membership functions of the node $\mathrm{A}$, while node $i$ comprises of $x$ or $y$ as its input, and $A i$ or $B i-1$ is a connected verbal label. $O_{j, i}$ is the membership score of sets A and B fuzzy. The global function of the non-linear constraints is presented in equation (7) [46] and[16]

$$
\mu_{A i}\left(x_{i}\right)=\frac{1}{1+\left(\frac{x-c_{i}}{a_{i}}\right)^{2 b_{i}}}
$$

where $a_{i}, b_{i}, c_{i}$ are the sets of variable. This function varies as the values of the variable changes, hence exhibiting diverse membership functions type for fuzzy set A.

Layer 2: Signals coming from layer one are multiplied and the results are sent out as the output of this layer. The 
output is deliberated as an AND or OR procedure of the membership function that comes from preceding layer [47]. It is presented in equation 8

$$
O_{i, 2}=w_{i}=\mu_{A_{i}} \times \mu_{B_{i}} \times \mu_{C_{i}} \ldots \ldots \ldots
$$

Where $\mu_{A i}$ denotes the membership function of node $\mathrm{A}$ and $\mu_{B i}$ is the membership function of node $\mathrm{B}$

Layer 3: Layer three is called the normalization layer and a non-adaptive layer, this layer usually make the rules. The ratio of the node's firing strength to the sum of all the firing strengths going into the node. This layer is non-adaptive layer [48].

$$
O_{i, 3}=\overline{w_{l}}=\frac{w_{i}}{w_{1}+w_{2}+\cdots}
$$

$w_{i}$ represents the firing strengths

Layer 4: all the nodes in layer four are adaptive nodes with node function. This means the product of the signal controlled from the preceding node gives node $i$ [49],[48].

$$
O_{i, 4}=\bar{w}_{l} f_{1}=\bar{w}_{l}\left(p_{i} x+q_{i} y+r_{i}\right)
$$

$\overline{w_{l}}$ is the normalized firing strength of node $i$ from the third layer and $p_{1}, q_{1}$ and $r_{1}$ are the subsequent parameters

Layer 5: This is the last layer of the ANFIS structure that consists a single node, this node is non-adaptive and also called a fixed node. It is the summation of all signals that come from the preceding layer and compute them as the total output $[44,47]$.

$$
O_{i, 5}=\sum_{i} \bar{w}_{l} f_{i}
$$

where $f_{i}$ is summation of the subsequent parameters of the fourth layer.

\subsection{Model Statistical Evaluators}

The PSO-ANFIS model performance is evaluated using the statistical evaluators in equations (12 and 13)

\section{Root mean square error (RMSE)}

$$
R M S E=\sqrt{\frac{\sum_{i=1}^{n}\left(O_{i}-\bar{P}_{l}\right)^{2}}{n}}
$$

\section{Coefficient of determination $\left(R^{2}\right)$}

$$
R^{2}=\frac{\sum_{i=1}^{n}\left(o_{i}-\overline{o_{l}}\right)^{2} \cdot\left(P_{i}-\overline{P_{l}}\right)}{\sum_{i=1}^{n}\left(O_{i}-\overline{O_{l}}\right) \cdot \sum_{i=1}^{n}\left(P_{i}-\bar{P}_{l}\right)}
$$

where $O_{i}$ and $P_{i}$ are the estimated and experimental values, and $\bar{O}_{i}$ and $\bar{P}_{i}$ are average values of $O_{i}$ and $P_{i}$. Also, n represents the entire amount of test data. Higher values of $R^{2}$ indicates good model performance while lower RMSE value also show good performance.

\subsection{MODEL TRAINING AND TESTING}

For this study, monthly mean relative humidity sunshine hours, minimum temperature and maximum temperature for the period of (2002-2012) were the data set used for the solar radiation prediction. $70 \%$ of the data were used to train the model while $30 \%$ were used to test the model. The model development was performed on MATLAB 2017a environment. The same proportion of data was used for training and testing all the models (ANFIS, PSO-ANFIS and GA-ANFIS).

\subsection{Hybrid ANFIS-PSO Model Development}

This section describes the procedure used in developing the proposed model as presented in Figure 4 and Figure 5 as the flowchart and the schematic diagram respectively. The hybrid approach in this study is the combination of ANFIS and PSO. The prediction is performed using ANFIS while the PSO is used in improving the performance of the ANFIS model. This is done to reduce the error by altering the parameters of the membership function required as presented in Table 1. Four input parameters, monthly mean (relative humidity sunshine hours, minimum temperature and maximum temperature) and monthly mean solar radiations were used in training and testing the PSO-ANFIS model. The monthly average data used for the study were divided into two sets, $70 \%$ of the data set (2002-2008) were used to train the model while $30 \%$ of the remaining data (2009-2012) were used for to test the model. The predicted signals from the PSO-ANFIS model gives the predicted solar radiation output.

The dataset used for this study were presented in a matrix form on an excel sheet, these datasets are presented in columns with 4 columns as inputs and 1 column as output. The number of columns of the input data represents the real inputs. The ANFIS is then trained using the data set presented. The least square estimation (LSE) in the forward pass and the Gradient Descent (GD) in the backward pass in the ANFIS structure are used as default training algorithm during the training. The consequent parameters are determined by the LSE in the forward pass, and the GD updates the membership function parameters in the backward pass. The system parameters are adjusted as inputs/outputs during the training process. The same applies during the testing process for the data that has not been used during the training process.

To obtain more accurate results, the ANFIS membership function parameters are trained using PSO, with the PSO replacing the GD in the backward pass. This is done by creating an $\mathrm{N}$-dimension vector where $\mathrm{N}$ represents number of membership functions. The PSO algorithm optimizes the parameters of the membership function contained in the vector. The PSO algorithm parameters are then defined and initialized randomly during the first stage. The PSO algorithm then keeps updating these parameters by updating one parameter of the membership function during each iteration. This update continues from iteration to iteration until we obtain the best possible solution by obtaining a minimum error set. The ANFIS output is then extracted using the parameters obtained by the PSO, and this output gives the predicted output of the proposed hybrid PSO-ANFIS model. 
Table 1. PSO parameters used

\begin{tabular}{|l|c|}
\hline Parameters & Values \\
\hline No. of particles & 25 \\
\hline Number of iterations & 1500 \\
\hline Cognitive acceleration C1 & 1 \\
\hline C2 & 1 \\
\hline Initial weight & 0.99 \\
\hline Final inertia & 1 \\
\hline
\end{tabular}

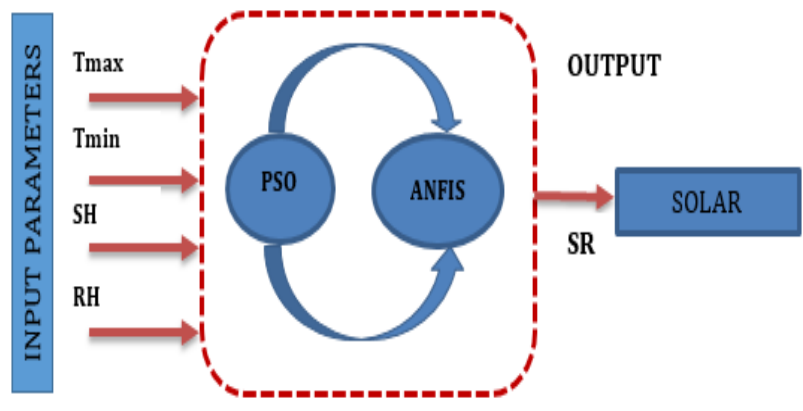

Figure 4. Schematic diagram of the developed ANFISPSO model

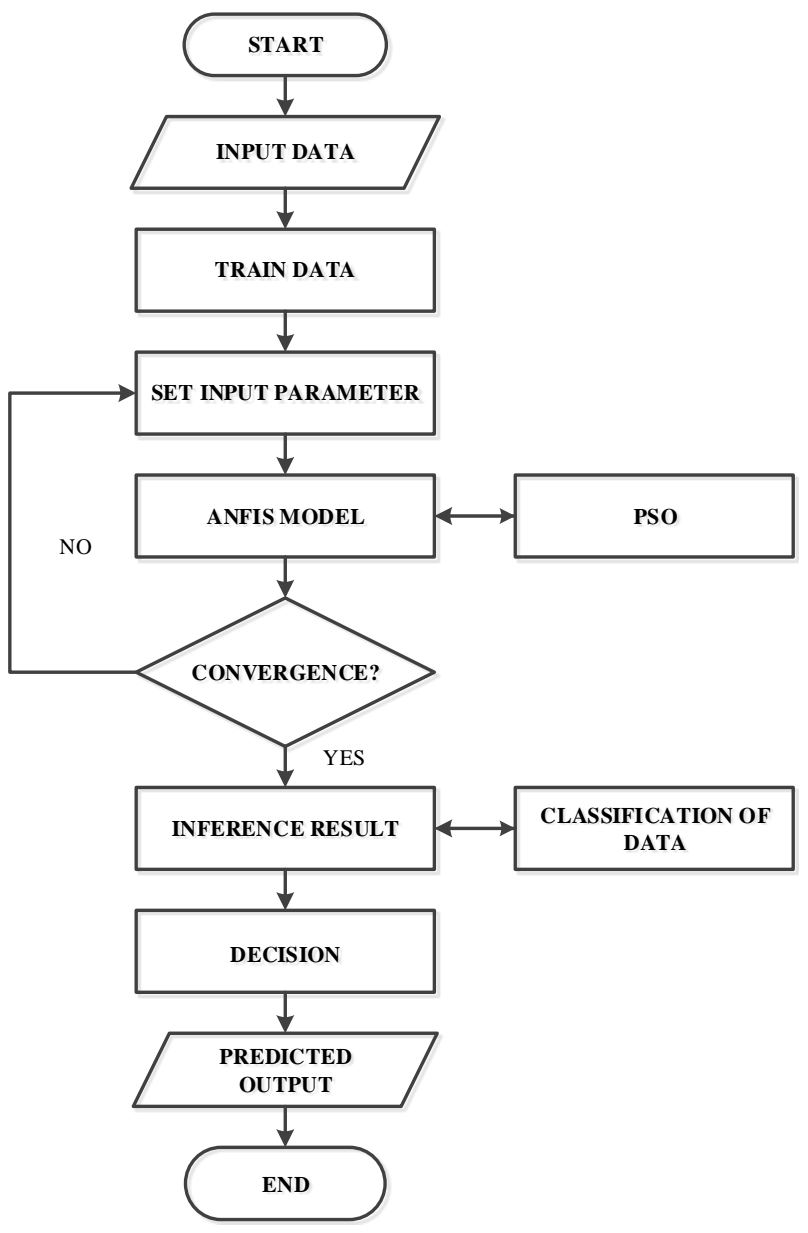

Figure 5. Flowchart of the proposed solar radiation prediction model

\subsection{RESULTS AND DISCUSSION}

In this study, the accuracy of hybrid PSO-ANFIS is examined for horizontal solar radiation prediction in Nigeria, meteorological data ranging from 2002-2012 were used for the study. The model is developed using four meteorological data (relative humidity sunshine hours, minimum temperature and maximum temperature) as inputs to the simulated solar radiation. The data used for the prediction were divided into two, $70 \%$ were used during the training phase and $30 \%$ were used during the testing phase. Three statistical evaluators RMSE and $\mathrm{R}^{2}$ were used for the model performance evaluation of the developed model.

The results obtained are presented in Figures 6 and 7, while the model performance results are presented in Table 2. Figure 6 (a, c and e) presents the scatter plots of the developed solar radiation models at the training stage, while Figure 6 (b, d and f) presents the scatter plots of the developed solar radiation models at the testing stage.

Table 2. Model performance analysis

\begin{tabular}{|c|c|c|c|}
\hline Model & & RMSE & $\mathbf{R}^{\mathbf{2}}$ \\
\hline & & & \\
& Training & $\mathbf{0 . 6 8 3 2}$ & $\mathbf{0 . 9 0 6 5}$ \\
& Testing & $\mathbf{1 . 3 8 3 8}$ & $\mathbf{0 . 8 0 5 8}$ \\
& & & \\
\hline & & & \\
GA-ANFIS & Training & $\mathbf{1 . 0 3 0 9}$ & $\mathbf{0 . 7 9 2 2}$ \\
& Testing & $\mathbf{1 . 3 0 0 8}$ & $\mathbf{0 . 8 3 8 5}$ \\
& & & \\
\hline \multirow{2}{*}{ ANFIS } & & & \\
& Training & $\mathbf{0 . 8 0 9 3}$ & $\mathbf{0 . 8 6 8 8}$ \\
& Testing & $\mathbf{1 . 6 9 5 4}$ & $\mathbf{0 . 7 3 6 3}$ \\
\hline
\end{tabular}

From the scatter plots presented, it clearly shows that there is clear agreement between the estimated and targeted solar radiation as a result of the dotted spots falling within the diagonal line. After comparing the PSOANFIS, GA-ANFIS and the ANFIS models, it is observed that the PSO-ANFIS has better accuracy for solar radiation prediction because it has a better convergence compared to the other two models.

Figure 7 shows the comparative prediction of the horizontal solar radiation using the three ANFIS models for model validation. The three models prove to have a very good prediction abilities for horizontal solar radiation prediction, but the PSO-ANFIS model has a better predicting ability than the other two models. The precision and accuracy of the PSO-ANFIS model is better than the other two models as presented in Figure 7. 


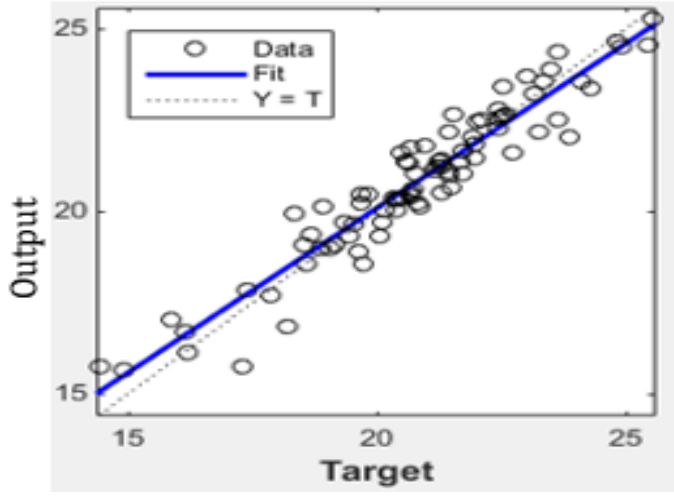

(a). HPA Training

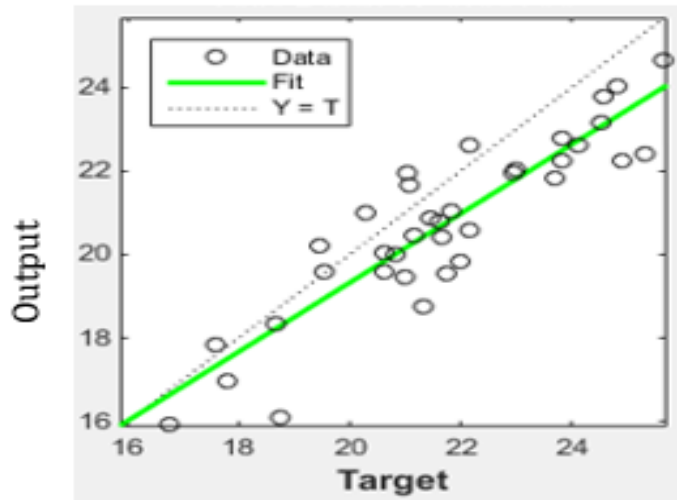

(b). HPA Testing

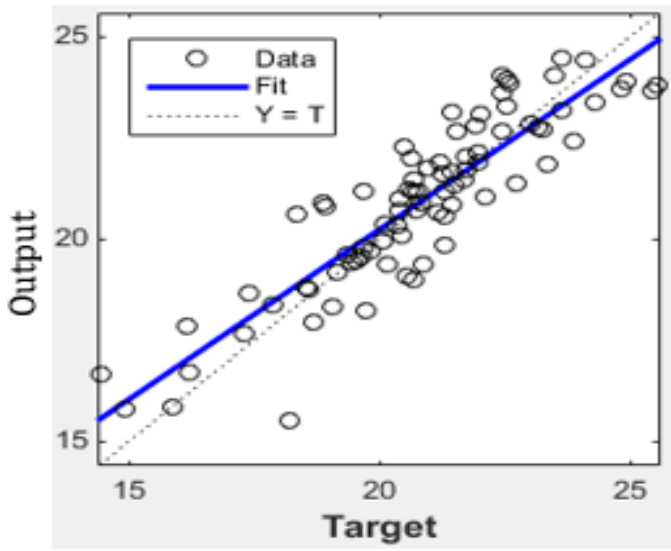

(c). ANFIS-GA Training

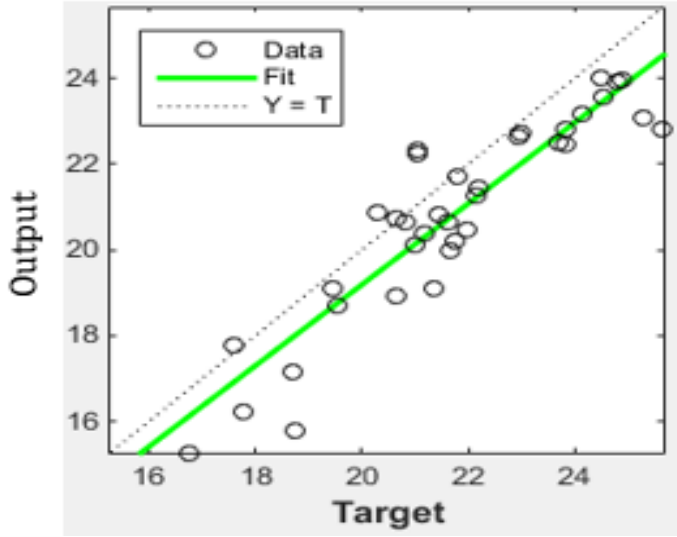

(d). ANFIS-GA Testing

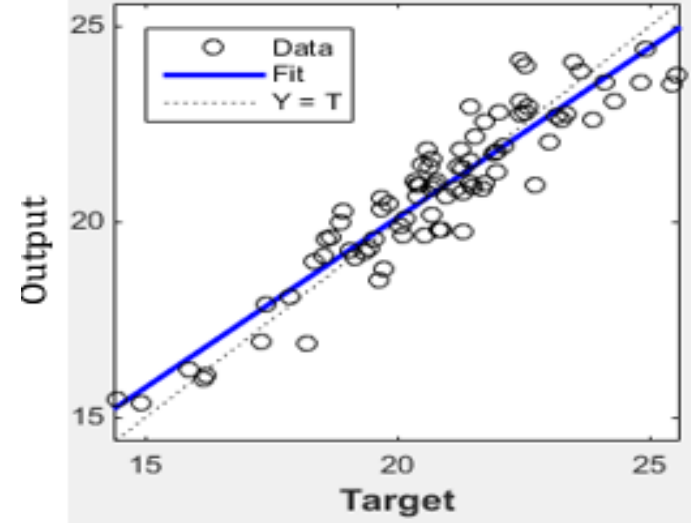

(e). ANFIS Training

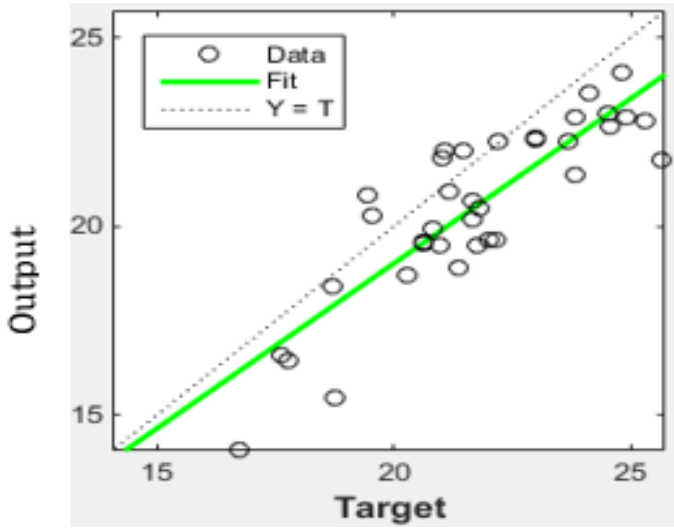

(f). ANFIS Training

Figure 6 (a-f). Scatter plot of the three models

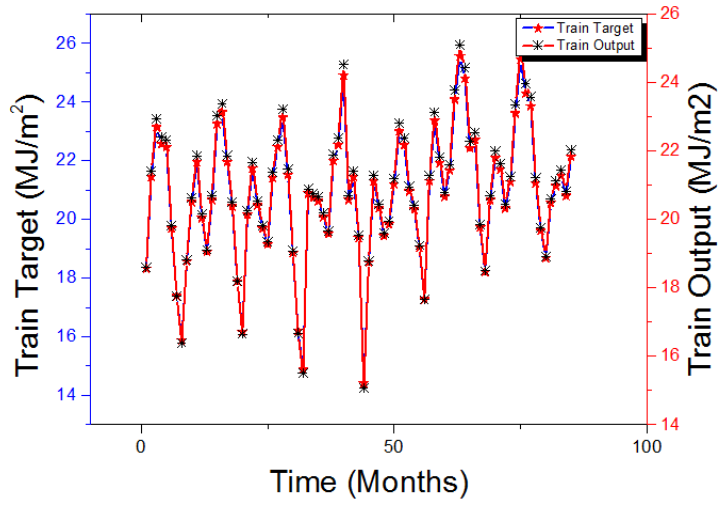

(a). ANFIS-PSO Training

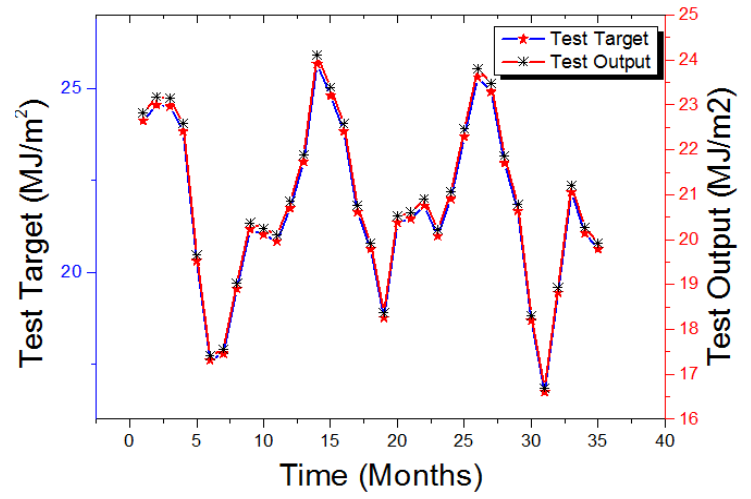

(b). ANFIS-PSO Testing 


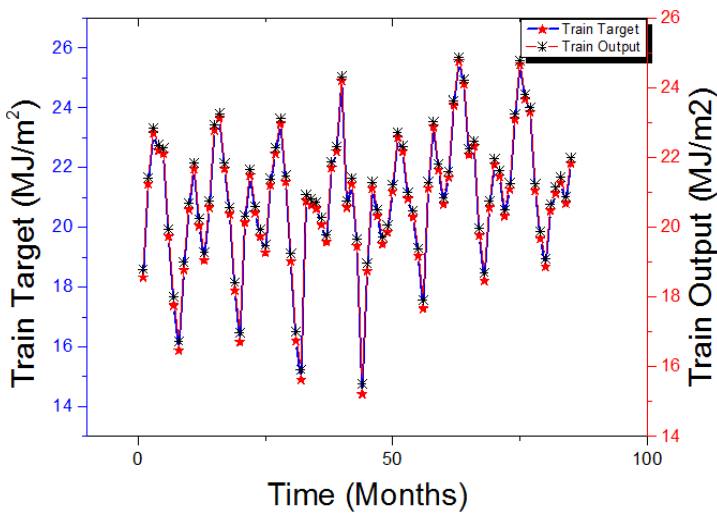

(c). ANFIS-GA Training

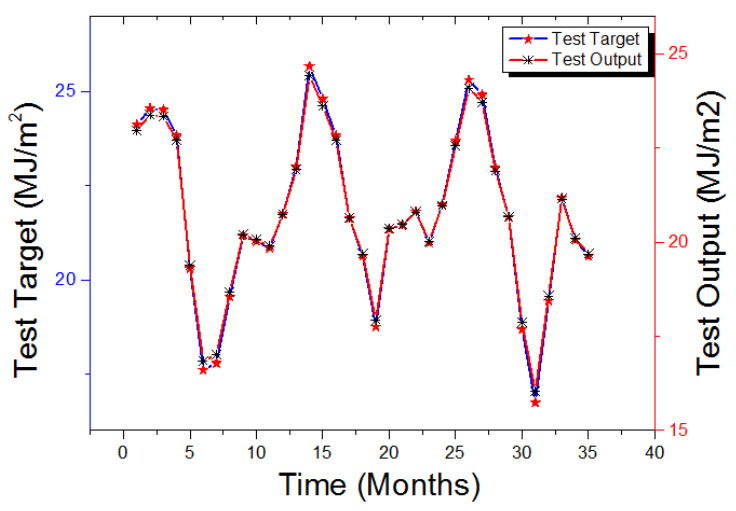

(d). ANFIS-GA Testing

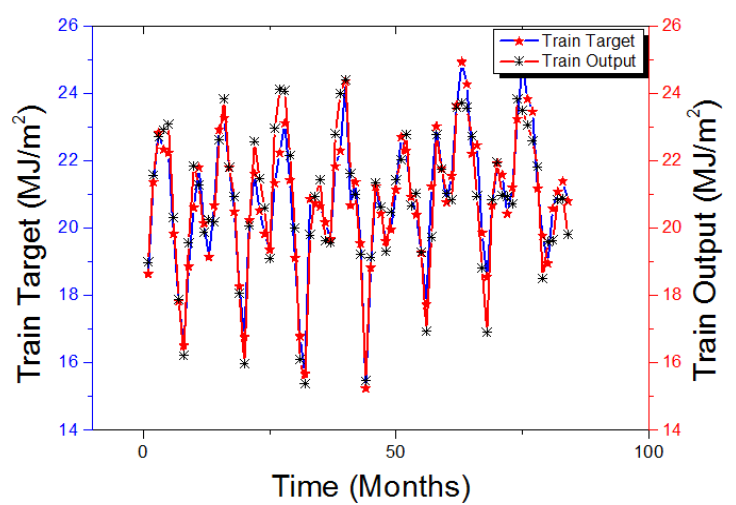

(e). ANFIS Training

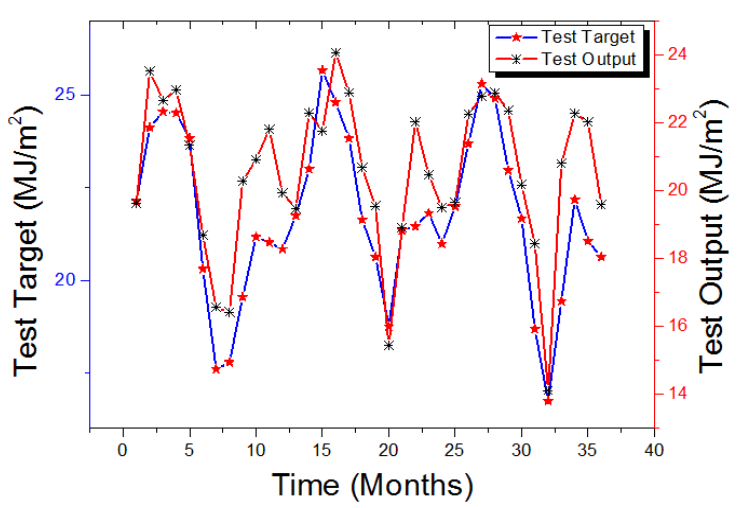

(f). ANFIS Testing

Figure 7 (a-f). Comparison between predicted outputs against the measured output
Table 3. Comparison of present study with existing literatures

\begin{tabular}{|c|c|c|c|c|}
\hline Reference & $\begin{array}{c}\text { Model } \\
\text { Used }\end{array}$ & $\begin{array}{c}\text { Case } \\
\text { Study }\end{array}$ & $\mathbf{R}^{2}$ & RMSE \\
\hline $\begin{array}{c}\text { Olatomiwa et } \\
\text { al [7] }\end{array}$ & ANFIS & Nigeria & 0.8544 & 1.0854 \\
\hline $\begin{array}{c}\text { Olatomiwa et } \\
\text { al [23] }\end{array}$ & $\begin{array}{c}\text { SVM- } \\
\text { FFA }\end{array}$ & Nigeria & 0.8024 & 0.6988 \\
\hline Sani et al [15] & ANFIS & Nigeria & 0.8688 & 0.8093 \\
\hline $\begin{array}{c}\text { Sajid and Ali } \\
{[50]}\end{array}$ & ANFIS & $\begin{array}{c}\text { Abu- } \\
\text { Dhabi }\end{array}$ & 0.8600 & - \\
\hline $\begin{array}{c}\text { Remedani et at } \\
{[51]}\end{array}$ & ANN & Iran & 0.7992 & 3.700 \\
\hline Present study & $\begin{array}{c}\text { PSO- } \\
\text { ANFIS }\end{array}$ & Nigeria & $\mathbf{0 . 9 0 6 5}$ & $\mathbf{0 . 6 8 3 2}$ \\
\hline
\end{tabular}

\subsection{CONCLUSION}

In this study, the accuracy of PSO-ANFIS method for solar radiation prediction in Nigeria is investigated using the available meteorological data. The proposed model is based on the combination of ANFIS and PSO. The result obtained from this study show beyond doubt that PSOANFIS is an excellent model for solar radiation prediction. Two other models GA-ANFIS and ANFIS were developed and compared with the PSO-ANFIS to affirm the accuracy of the model. Tmin, Tmax, $\mathrm{SH}$ and $\mathrm{RH}$ ranging from (2002-2012) were used as input to the model. Two statistical evaluators namely RMSE and $\mathrm{R}^{2}$ were used to assess the model performance. From the study, PSOANFIS has $\mathbf{R M S E}=\mathbf{0 . 6 8 3 1 8}$ and $\mathbf{R}^{\mathbf{2}}=\mathbf{0 . 9 0 6 5}$ during the training stage, and $\mathbf{R M S E}=\mathbf{1 . 3 8 3 8}$ and $\mathbf{R}^{\mathbf{2}}=\mathbf{0 . 8 0 5 8}$ during the testing stage. The GA-ANFIS has RMSE $=\mathbf{1 . 0 3 0 9}$ and $\mathbf{R}^{\mathbf{2}}=\mathbf{0 . 7 9 2 2}$ during the training stage and $\mathbf{R M S E}=\mathbf{1 . 3 0 0 8}$ and $\mathbf{R}^{\mathbf{2}}=\mathbf{0 . 8 3 8 5}$ during the testing stage. The ANFIS model also has the $\mathbf{R M S E}=\mathbf{0 . 8 0 9 3}$ and $\mathbf{R}^{\mathbf{2}}=\mathbf{0 . 8 6 8 8}$ during the training stage and $\mathbf{R M S E}=\mathbf{1 . 6 9 5 4}$ and $\mathbf{R}^{2}=\mathbf{0 . 7 3 6 3}$ during the testing stage. From the statistical results presented in Table 2, it clearly shows that PSO-ANFIS has lower RMSE value and higher $\mathrm{R}^{2}$ values compared to the other two models. The model result was also compared with existing literature as shown in Table 3. Based on the results obtained, it is evident that PSO-ANFIS outperformed the GA-ANFIS, ANFIS and the benchmarked models for horizontal solar radiation prediction. Therefore, optimizing ANFIS with PSO has a better accuracy for solar radiation prediction and also has the potential for solar radiation prediction in Nigeria.

\section{REFERENCES}

[1] A. Trabea and M. M. Shaltout, "Correlation of global solar radiation with meteorological parameters over Egypt," Renewable Energy, vol. 21, pp. 297-308, 2000.

[2] K. Chiteka and C. Enweremadu, "Prediction of global horizontal solar irradiance in Zimbabwe using artificial neural networks," Journal of Cleaner Production, vol. 135, pp. 701-711, 2016.

[3] T. N. Veziroglu, "21st Century's energy: hydrogen energy system," in Assessment of Hydrogen Energy 
for Sustainable Development, ed: Springer, 2007, pp. 9-31.

[4] A. Contreras, R. Guirado, and T. Veziroglu, "Design and simulation of the power control system of a plant for the generation of hydrogen via electrolysis, using photovoltaic solar energy," International Journal of Hydrogen Energy, vol. 32, pp. 4635-4640, 2007.

[5] M. Santarelli, M. Calì, and S. Macagno, "Design and analysis of stand-alone hydrogen energy systems with different renewable sources," International Journal of Hydrogen Energy, vol. 29, pp. 1571-1586, 2004.

[6] M. Alam, S. K. Saha, M. Chowdhury, M. Saifuzzaman, and M. Rahman, "Simulation of solar radiation system," American Journal of Applied Sciences, vol. 2, pp. 751-758, 2005.

[7] L. Olatomiwa, S. Mekhilef, S. Shamshirband, and D. Petković, "Adaptive neuro-fuzzy approach for solar radiation prediction in Nigeria," Renewable and Sustainable Energy Reviews, vol. 51, pp. 1784-1791, 2015.

[8] A. Angstrom, "Solar and terrestrial radiation. Report to the international commission for solar research on actinometric investigations of solar and atmospheric radiation," Quarterly Journal of the Royal Meteorological Society, vol. 50, pp. 121-126, 1924.

[9] B. Yaniktepe and Y. A. Genc, "Establishing new model for predicting the global solar radiation on horizontal surface," International Journal of Hydrogen Energy, vol. 40, pp. 15278-15283, 2015.

[10] H. Khorasanizadeh, K. Mohammadi, and N. Goudarzi, "Prediction of horizontal diffuse solar radiation using clearness index based empirical models; A case study," International Journal of Hydrogen Energy, vol. 41, pp. 21888-21898, 2016.

[11] J. Zhang, L. Zhao, S. Deng, W. Xu, and Y. Zhang, "A critical review of the models used to estimate solar radiation," Renewable and Sustainable Energy Reviews, vol. 70, pp. 314-329, 2017.

[12] O. Şenkal and T. Kuleli, "Estimation of solar radiation over Turkey using artificial neural network and satellite data," Applied Energy, vol. 86, pp. 12221228, 2009.

[13] J. Qin, Z. Chen, K. Yang, S. Liang, and W. Tang, "Estimation of monthly-mean daily global solar radiation based on MODIS and TRMM products," Applied energy, vol. 88, pp. 2480-2489, 2011.

[14] M. Benghanem, A. Mellit, and S. Alamri, "ANNbased modelling and estimation of daily global solar radiation data: A case study," Energy conversion and management, vol. 50, pp. 1644-1655, 2009.

[15] S. Salisu, M. Mustafa, and M. Mustapha, "Predicting Global Solar Radiation in Nigeria Using Adaptive Neuro-Fuzzy Approach," in International Conference of Reliable Information and Communication Technology, 2017, pp. 513-521.

[16] G. Landeras, J. J. López, O. Kisi, and J. Shiri, "Comparison of Gene Expression Programming with neuro-fuzzy and neural network computing techniques in estimating daily incoming solar radiation in the Basque Country (Northern Spain),"
Energy conversion and management, vol. 62, pp. 113, 2012.

[17] J. Piri, S. Shamshirband, D. Petković, C. W. Tong, and M. H. ur Rehman, "Prediction of the solar radiation on the Earth using support vector regression technique," Infrared Physics \& Technology, vol. 68, pp. 179-185, 2015.

[18] S. Bhardwaj, V. Sharma, S. Srivastava, O. Sastry, B. Bandyopadhyay, S. Chandel, et al., "Estimation of solar radiation using a combination of Hidden Markov Model and generalized Fuzzy model," Solar Energy, vol. 93, pp. 43-54, 2013.

[19] J. Wu, C. K. Chan, Y. Zhang, B. Y. Xiong, and Q. H. Zhang, "Prediction of solar radiation with genetic approach combing multi-model framework," Renewable Energy, vol. 66, pp. 132-139, 2014.

[20] S. Shamshirband, K. Mohammadi, L. Yee, D. Petković, and A. Mostafaeipour, "A comparative evaluation for identifying the suitability of extreme learning machine to predict horizontal global solar radiation," Renewable and Sustainable Energy Reviews, vol. 52, pp. 1031-1042, 2015.

[21] K. Mohammadi, S. Shamshirband, C. W. Tong, M. Arif, D. Petković, and S. Ch, "A new hybrid support vector machine-wavelet transform approach for estimation of horizontal global solar radiation," Energy Conversion and Management, vol. 92, pp. 162-171, 2015.

[22] Y. Feng, N. Cui, Q. Zhang, L. Zhao, and D. Gong, "Comparison of artificial intelligence and empirical models for estimation of daily diffuse solar radiation in North China Plain," International Journal of Hydrogen Energy, vol. 42, pp. 14418-14428, 2017.

[23] L. Olatomiwa, S. Mekhilef, S. Shamshirband, K. Mohammadi, D. Petković, and C. Sudheer, "A support vector machine-firefly algorithm-based model for global solar radiation prediction," Solar Energy, vol. 115, pp. 632-644, 2015.

[24] O. Chapelle, V. Vapnik, O. Bousquet, and S. Mukherjee, "Choosing multiple parameters for support vector machines," Machine learning, vol. 46, pp. 131-159, 2002.

[25] J. Huang, M. Korolkiewicz, M. Agrawal, and J. Boland, "Forecasting solar radiation on an hourly time scale using a Coupled AutoRegressive and Dynamical System (CARDS) model," Solar Energy, vol. 87, pp. 136-149, 2013.

[26] X. Xue, "Prediction of daily diffuse solar radiation using artificial neural networks," International Journal of Hydrogen Energy, vol. 42, pp. 28214 28221, 2017.

[27] H. M. I. Pousinho, V. M. F. Mendes, and J. P. d. S. Catalão, "A hybrid PSO-ANFIS approach for shortterm wind power prediction in Portugal," Energy Conversion and Management, vol. 52, pp. 397-402, 2011.

[28] H. M. I. Pousinho, V. M. F. Mendes, and J. P. d. S. Catalão, "Short-term electricity prices forecasting in a competitive market by a hybrid PSO-ANFIS approach," International Journal of Electrical Power \& Energy Systems, vol. 39, pp. 29-35, 2012. 
[29] X. Yuan, L. Wang, and Y. Yuan, "Application of enhanced PSO approach to optimal scheduling of hydro system," Energy Conversion and Management, vol. 49, pp. 2966-2972, 2008.

[30] J. Catalao, H. Pousinho, and V. Mendes, "Hybrid wavelet-PSO-ANFIS approach for short-term wind power forecasting in Portugal," IEEE Transactions on Sustainable Energy, vol. 2, pp. 50-59, 2011.

[31] J. P. d. S. Catalão, H. M. I. Pousinho, and V. M. F. Mendes, "Hybrid wavelet-PSO-ANFIS approach for short-term electricity prices forecasting," IEEE Transactions on Power Systems, vol. 26, pp. 137-144, 2011.

[32] H. Basser, H. Karami, S. Shamshirband, S. Akib, M. Amirmojahedi, R. Ahmad, et al., "Hybrid ANFISPSO approach for predicting optimum parameters of a protective spur dike," Applied Soft Computing, vol. 30, pp. 642-649, 2015.

[33] Y. Al-Dunainawi, M. F. Abbod, and A. Jizany, "A new MIMO ANFIS-PSO based NARMA-L2 controller for nonlinear dynamic systems," Engineering Applications of Artificial Intelligence, vol. 62, pp. 265-275, 2017.

[34] M. Rezakazemi, A. Dashti, M. Asghari, and S. Shirazian, "H 2-selective mixed matrix membranes modeling using ANFIS, PSO-ANFIS, GA-ANFIS," International Journal of Hydrogen Energy, 2017.

[35] M. Anemangely, A. Ramezanzadeh, and B. Tokhmechi, "Shear wave travel time estimation from petrophysical logs using ANFIS-PSO algorithm: A case study from Ab-Teymour Oilfield," Journal of Natural Gas Science and Engineering, vol. 38, pp. 373-387, 2017.

[36] T. Çavdar, "PSO tuned ANFIS equalizer based on fuzzy C-means clustering algorithm," AEUInternational Journal of Electronics and Communications, vol. 70, pp. 799-807, 2016.

[37] R. Eberhart and J. Kennedy, "A new optimizer using particle swarm theory," in Micro Machine and Human Science, 1995. MHS'95., Proceedings of the Sixth International Symposium on, 1995, pp. 39-43.

[38] X. Li and A. P. Engelbrecht, "Particle swarm optimization: an introduction and its recent developments," in Proceedings of the 9th annual conference companion on Genetic and evolutionary computation, 2007, pp. 3391-3414.

[39] S. Raj, K. C. Ray, and O. Shankar, "Cardiac arrhythmia beat classification using DOST and PSO tuned SVM," Computer methods and programs in biomedicine, vol. 136, pp. 163-177, 2016.
[40] W. Yu and X. Li, "Fuzzy identification using fuzzy neural networks with stable learning algorithms," IEEE Transactions on Fuzzy Systems, vol. 12, pp. 411-420, 2004.

[41] P. P. Bonissone, "Soft computing: the convergence of emerging reasoning technologies," Soft computing, vol. 1, pp. 6-18, 1997.

[42] M. Gil, E. Sarabia, J. Llata, and J. Oria, "Fuzzy cmeans clustering for noise reduction, enhancement and reconstruction of 3D ultrasonic images," in Emerging Technologies and Factory Automation, 1999. Proceedings. ETFA'99. 1999 7th IEEE International Conference on, 1999, pp. 465-472.

[43] K. Mohammadi, S. Shamshirband, A. S. Danesh, M. S. Abdullah, and M. Zamani, "Temperature-based estimation of global solar radiation using soft computing methodologies," Theoretical and Applied Climatology, pp. 1-12, 2015.

[44] J.-S. Jang, "ANFIS: adaptive-network-based fuzzy inference system," IEEE transactions on systems, man, and cybernetics, vol. 23, pp. 665-685, 1993.

[45] M. Mustapha, M. Mustafa, S. Khalid, I. Abubakar, and A. M. Abdilahi, "Correlation and Wavelet-based Short-Term Load Forecasting using Anfis," Indian Journal of Science and Technology, vol. 9, 2016.

[46] F. Kocabaş and Ş. Ülker, "Estimation of critical submergence for an intake in a stratified fluid media by neuro-fuzzy approach," Environmental Fluid Mechanics, vol. 6, pp. 489-500, 2006.

[47] J.-S. R. Jang, C.-T. Sun, and E. Mizutani, "Neurofuzzy and soft computing; a computational approach to learning and machine intelligence," 1997.

[48] T. Nguyen and Y. Liao, "Short-Term Load Forecasting Based on Adaptive Neuro-Fuzzy Inference System," Journal of computers, vol. 6, pp. 2267-2271, 2011.

[49] M. Sugeno and G. Kang, "Structure identification of fuzzy model," Fuzzy sets and systems, vol. 28, pp. 1533, 1988.

[50] S. Hussain and A. AlAlili, "A hybrid solar radiation modeling approach using wavelet multiresolution analysis and artificial neural networks," Applied Energy, 2017.

[51] Z. Ramedani, M. Omid, A. Keyhani, S. Shamshirband, and B. Khoshnevisan, "Potential of radial basis function based support vector regression for global solar radiation prediction," Renewable and Sustainable Energy Reviews, vol. 39, pp. 1005-1011, 2014. 